\title{
TRATAMENTO DA MASTITE BOVINA PELA HOMEOPATIA: UMA REVISÃO
}

BEZERRA, Fernanda de Campos ${ }^{1}$ LIMA, Erico da Silva ${ }^{2}$ VALENTE, Tiago Neves Pereira ${ }^{3}$

Recebido em: 2020.04.15 Aprovado em: 2020.10.30 ISSUE DOI: 10.3738/21751463.3770

RESUMO: A preocupação dos consumidores em adquirem produtos de melhor qualidade fez aumentar a demanda por produtos orgânicos que fossem mais saudáveis, mas a bovinocultura de leite no Brasil ainda não conseguiu se adequar a essa exigência e em muitas propriedades os antibióticos ainda são usados de forma indiscriminada e uma menor parcela utiliza a homeopatia. Entretanto, a eficácia dos medicamentos homeopáticos ainda hoje é duvidosa, sendo alvo de estudos em vários países. O objetivo dessa revisão foi abordar os últimos estudos homeopáticos na criação de bovinos no Brasil a fim de verificar a eficiência de uso do medicamento. Os defensores da homeopatia afirmam que a falta de conhecimento apropriado do médico veterinário junto com outros entraves de manejo é a causa da baixa eficácia do medicamento, enquanto para outros autores ela não apresentaria resultado nenhum. As pesquisas no campo homeopático carecem de mais investigação, de novas publicações e de divulgação.

Palavras-chave: Antibióticos. Bovino. Homeopatia. Mastite. Tratamento.

\section{TREATMENT OF BOVINE MASTITIS FOR HOMEOPATHY: A REVIEW}

SUMMARY: The concern of consumers to purchase better quality products has increased the demand for healthier organic products, but Brazilian dairy cattle still cannot adapt to this requirement and in many properties, antibiotics are still used indiscriminately, and a smaller farmer uses homeopathy. However, the efficacy of homeopathic medicines is still doubtful today, being studied in several countries. The objective of this review was to discuss the last homeopathic studies on cattle breeding in Brazil in order to verify the efficiency of the use of the drug. Proponents of homeopathy claim that the lack of proper knowledge of the veterinarian along with other barriers is the cause of the low efficacy of the drug, while for other authors it would not yield any results. Research in the homeopathic field needs more research, new publications and dissemination.

Keywords: Antibiotics. Cattle. Homeopathy. Mastitis. Treatment

\section{INTRODUÇÃO}

Segundo o IBGE (2018), a produção de leite no Brasil chegou a 35,1 bilhões de litros sendo que apenas 24,7 bilhões de litros foi inspecionada (NEIVA, 2019).

É cada vez maior a procura por produtos orgânicos no crescente mercado consumidor, em 2015 esse mercado já movimentava cerca de US\$ 634,52 (POZZI; NETO, 2017). Isso se deve ao aumento do número de produtos com quimiossintéticos usados na pecuária que têm deixado resíduos químicos nos produtos prejudicando a saúde humana, pois não há a espera adequada para a carência desses medicamentos em muitas propriedades. Fora isso, o mercado consumidor também está preocupado com o próprio bem-estar animal e ambiental (ROSSI ; LEMOS, 2013).

Procurando atender as perspectivas do mercado consumidor atual e ainda provomer o bem-estar animal tornando os rebanhos mais saudáveis e consequentemente mais produtivos,

\footnotetext{
${ }^{1}$ Centro Universitário das Faculdades Metropolitanas Unidas, FMU

${ }^{2}$ Centro Universitário Campo Limpo Paulista, UNIFACCAMP

${ }^{3}$ Instituto Federal Goiano, Campus Posse
} 
produtores começaram a investir e substituir a enorme bateria de produtos farmacêuticos como antibióticos, anti-helmínticos entre outros, por farmácos naturais como os fitoterápicos e homeopáticos, aumentando assim a produção de alimentos orgânicos, embora a utilização dessas técnicas sejam questionavéis por conta de maiores comprovações (ROSSI, 2013)

Fornecer uma alimentação de qualidade aos consumidores, não é apenas o intuíto de um sistema de produção orgânico, segundo a Instrução Normativa N46 de 06 de Outubro de 2011, o bem estar dos animais durante todos os processos é primordial, os cuidados vão da higiene, alimentação e água de qualidade, ao respeito com cada espécie, instalações adequadas, manejo de descarte ambientalmente correto de seus resíduos além do cumprimento com o calendário de vacinas obrigátorias estipuladas pela legislação, tudo isso são partes de ações preventivas que visam no final de tudo, a qualidade do produto na mesa dos consumidores (ROSSI; LEMOS, 2013)

As boas práticas de higiene, durante a ordenha, são requisitos imprescindíveis para os rebanhos orgânicos leiteiros evitando o uso de fármacos. O uso de antibióticos, segundo a legislação orgânica, não é proibido, mas se faz necessário que os produtos fornecidos por esses animais sejam identificados e classificados como não orgânicos (LEMOS, 2013)

A deficiência nas boas práticas de higiene no manejo durante e depois da ordenha é um problema grave, pois bactérias como o Staphylococcus aureus Staphylococcus coagulase negativo, Streptococcus agalactiae, Streptococcus uberis e Corynebacterium bovis, que coexistem naturalmente na flora da glândula mamária do animal podem gerar infecções, assim como também as bactérias oportunistas que vivem no ambiente de ordenha como a Escherichia coli, Klebsiella sp, Enterobacter sp, Pseudomonaaeroginosa e Streptococcus dysgalactiae que também podem diminuir a produção leiteira causando impactos negativos na sua economia, como o descarte precoce ou morte dos animais devido a perda do úbere que se torna reserva desses patógenos, há ainda o risco a saúde pública por ocasionar toxi-infecções na população (TRONCARELLI et al., 2013, CAMARGO, 2013; SAROLLI; ZIMERMANN ; IASCHOMBERCK, 2016). Há o investimento todo ano em novos medicamentos graças a resistência de microrganismos devido a má administração dos farmacos, por esse motivo novas terapias são necessárias (CAMARGO, 2013; LEAL ; COSTA, 2013)

Nesse estudo buscou analizar e comparar como as práticas alternativas, como a homeopatia, é aplicada no caso das mastites no gado leiteiro, fazendo-se eficaz ou não em propriedades brasileiras e de outros países, já que a mastite é um problema em qualquer parte do mundo e soluções naturais são cada vez mais procuradas. Em países como o Canadá, essas alternativas são usadas somente quando as convencionais não apresentam os efeitos desejados já em paises como a Espanha os convencionais não são utilizados (FRANCOZ et al., 2017). 


\section{A homeopatia na produção de bovinos}

Sendo muito preconizada dentro da medicina veterinária principalmente para os animais de produção, para tratamentos de doenças agudas e até mesmo crônicas, como mastite, problemas digestivos, problemas durante o parto além dos comportamentais a prática homeopática ganha cada vez mais destaque em países como a Espanha que até então usavam medicamentos alopáticos como antibioticos, apresentando resistência quanto ao uso de farmácos homeopáticos por desconhecimento sobre sua eficácia por parte dos produtores (ORJALES et al., 2016).

Para Alves (2015) a homeopatia entra como a alternativa mais viável e ecomônica, que nunca deve ser aplicada exclusivamente, sempre empregada com as boas práticas de manejo, onde pode ser realizada de forma individual ou coletiva, nesse último caso, o que determina o medicamento escolhido será a anamnese feita através do gênio epidêmico do rebanho. Em seu trabalho, cita a pesquisa de Honorato (2006) onde afirma que todo o sucesso com a criação leiteira acontece pelo manejo adequado e principalmente da convivência harmoniosa entre os manejadores, ordenhadores e animais, o que seria responsavél por transformar os hormonios que atuam durante a ordenha.

O leite orgânico apresenta maior teor protéico e de ácido linoléico conjugado, embora seu teor de gordura seja menor do que o convencional e o padrão de acidez seja diferente do que é estabelecido pela legislação, o que pode significar contaminação bacteriana em algum momento do processo de ordenha. Foram encontradas ainda, deficiência no manejo por conta do elevado número de células somáticas o mesmo foi descrito por Leal e Costa (2013) em sua pesquisa de contagem de células somáticas (CCS), os autores afirmam que o uso de homeopatia não apresentou eficácia na redução da CCS (ROSSI ; LEMOS, 2013).

No caso das propriedades que fazem uso do sistema convencional, os autores notaram que havia um grande número de bactérias termotolerantes no leite (ROSSI ; LEMOS, 2013), isso se daria pela perda da estabilidade térmica além das alterações nas propriedades nutritivas do leite como gorduras, aminoácidos e açúcares (LEAL ; COSTA, 2013).

A profilaxia realizada antes e depois da ordenha nas propriedades orgânicas é feita por emio de uma solução de iodo glicerinado com linhaça. Nos casos de mastite clínica o tratamento pode ser homeopático, fitoterápico associado com massagem no úbere usando pomadas de própolis ou ainda aplicação de argila, mas segundo Troncarelli et al. (2013) em suas observações, nenhuma dessas terapias apresentariam resultados satisfatórios, a responsável pela melhora do quadro clínico se restrigiria apenas ao uso do própolis devido sua ação bactericida.

Já para Arcanjo et al. (2017) o controle da mastite passa por 6 pontos importantes e indispensavéis, indo da correta rotina de higiene do ordenhador e animal passando por tratamento 
com antibióticos intramamários das mastites clínicas durante a lactação, secagem dos animais com antibioticoterapia, funcionamento adequado dos equipamentos de ordenha, isolamento após reconhecimento de animais cronicamente infectados e por último o adequado manejo do ambiente tanto higiênico como para o bem-estar dos animais. Em trabalhos resaltam, por exemplo, que a mosca dos estábulos (Stomoxys calcitrans) é descrita como um importante agente infeccioso de doenças como a mastite e doenças gastrointestinais aos bovinos por carrear a bactéria Escherichia col $i$. Outro fator apontado por Arcanjo et al. (2017) é a presença dos bezerros na hora da ordenha o que facilitaria a produção de ocitocina e aliviaria o estresse responsável pelo comportamento agressivo das vacas durante a ordenha.

Mas para Freitas (2015), a homeopatia associada a outras alternativas também tem sua eficácia se seus princípios forem respeitados desde o início. Em pesquisa realizada no múnicipio de Pontão, ao norte do Rio Grande do Sul, pode constatar que os produtos comprados em casas agropecuárias com formulações duvidosas que se diziam homeopáticas, não possuiam boa eficácia, levando os produtores a descrédito. Segundo o autor, essas formulações apresentam mais de um medicamento que são muitas vezes antagonicos entre si.

A anamnese é outro ponto importante na homeopatia. Ela leva em consideração as características físicas e mentais do paciente junto com seus sintomas mais proeminentes. Massignani (2015), em sua pesquisa realizada em duas propriedades de Santa Catarina, diagnosticou os animais utilizando-se do método "Gênio Epidêmico" durante a anamnese (repertorização do rebanho como único indivíduo). A Matéria Médica homeopáta precisa ser bem conhecida pelo médico veterinário em questão, assim como a atuação dos medicamentos no estado mental do paciente. No caso dos rebanhos o grupo é analisado como um ser único, sendo investigado não apenas as particularidades da doença, mas o que levou ao surto infeccioso (causa base de fundo psíquico), tudo que for particular e peculiar ao grupo deve ser avaliado. $\mathrm{O}$ medicamento escolhido deverá ser administrado a todos os individuos como tratamento para os membros afetados e de medida profilática para os outros (ALVES, 2015).

Já para Neufeldt et al. (2017) o sistema de confinamento dos animais influenciaria no estado mental desses, impedindo que o tratamento homeopático apresente os resultados esperados, pois segundo a doutrina homeopática esses animais nunca seriam considerados saúdaveis por estarem em um ambiente que limite suas vontades, além do fato do medicamento ser administrado em um período inferior ao recomentado. Por conta disso, as autoras também não encontraram diferenças na contagem de células somáticas de vacas tratadas com homeopátia em relaçao àquelas não tratadas.

Ebert et al. (2017), acompanharam grupos controles de bovinos tratados com placebo e medicamentos homeopáticos por 200 dias após o tratamento e não constataram diferenças Nucleus Animalium, v.12, n.2, nov.2020 
significativas no tempo de recuperação e nem na contagem de células somáticas no tratamento homeopático.

Nas observações de outros trabalhos homeopáticos realizados por Francoz et al. (2017), os autores também não encontraram nenhuma mudança significativa nos tratamentos da mastite com homeopátia, a única diferença que observaram foi a diminuição dos custos com medicamentos alopáticos. Os autores afirmam que apesar das indicações para os tratamentos alternativos não há muitas comprovações e evidências que provem a eficiência do tratamento homeopático.

A área da homeopátia necessita ser mais explorada e seus resultados codificados corretamente, afirmam Doehring and Sundrum (2016) que realizaram uma coletania de dados sobre o uso dos medicamentos homeopáticos em animais de produção de 1981 a 2014, onde demonstraram que os estudos sobre a técnica são imprecissos e que poucos resultados positivos foram obtidos. Também mencionaram que nos estudos analizados poucos veterinários homeopátas participaram e muitos dos medicamentos eram administrados por veterinários não especialistas onde impregavam o uso de mais de uma substância ao mesmo tempo. Segundo Massignani (2015), na homeopatia Unicista o indivíduo é tratado com um único medicamento homeopático que contemple desde sintomas gerais de comportamento a sintomas mentais e físicos.

Poucos autores pautaram suas pesquisas sobre o uso da homeopatia na mastite no Brasil nos últimos anos, assim, a escassez de dados, dificulta que demonstrem a comprovação no uso desses fármacos, embora a Tabela 1 demonstre que o uso adequado desses medicamentos, seguindo a orientação de um médico veterinário especialista apresenta bons resultados. 
Tabela 1 - Tratamento da mastite bovina por meio da homeopatia.

\begin{tabular}{|c|c|c|c|c|c|}
\hline Autores & $\begin{array}{l}\text { Propriedades } \\
\text { analisadas } \\
\end{array}$ & $\begin{array}{l}\text { Amostras de } \\
\text { animais }\end{array}$ & Local & $\begin{array}{l}\text { Medicamento } \\
\text { homeopático }\end{array}$ & resultados \\
\hline Massignani (2015) & 1 & 30 & Forquilhinha- SC & $\begin{array}{lll}\text { Unicista } & & \\
\text { Pulsatila } & 30,50,100,200 \mathrm{CH} \\
\text { Phytolacca } & 6 \mathrm{CH} \text { e } & 12 \mathrm{CH} \\
\text { (apenas } & \text { para } & \text { sinais } \\
\text { agudos) } & & \end{array}$ & satisfatório \\
\hline Massignani (2015) & 1 & 32 & Nova Veneza- SC & $\begin{array}{l}\text { Phosphorus } \\
30,50,100,200,300 \mathrm{CH}\end{array}$ & Satisfatório \\
\hline Freitas (2015) & 4 & 45 & Pontão- RS & $\begin{array}{l}\text { Unicista } \\
\text { Ignatia 200CH } \\
\text { *Pulsatilla } \\
\text { Phytolacca 30Ch } \\
\begin{array}{l}\text { Silicea 8CH e } \\
\text { Hepar sulphur 3CH }\end{array} \\
\text { HecH } \\
\end{array}$ & Satisfatório \\
\hline Freitas (2015) & 1 & 15 & Passo Fundo- RS & $\begin{array}{l}\text { Não unicista Composto } \\
\text { com vários medicamentos } \\
\text { comprado em lojas } \\
\text { agropecuárias }\end{array}$ & Insatisfatório \\
\hline Leal et al. (2013) & 1 & 48 & IraÍ- RS & $\begin{array}{l}\text { Não unicista } \\
\text { Carbo animalis } 12 \mathrm{CH} \\
\text { Phytolacca decandra } \\
12 \mathrm{CH} \\
\text { Sulphur } 12 \mathrm{CH} \\
\text { Lac vaccinum } 12 \mathrm{CH} \\
\text { Pulsattilla nigricans } 30 \mathrm{CH}\end{array}$ & Insatisfatório \\
\hline Muller et al. (2013) & 20 & 40 & $\begin{array}{l}\text { Marechal Cândido Rondon- } \\
\text { PR }\end{array}$ & $\begin{array}{l}\text { Unicista } \\
\text { Pulsatilla } 12 \mathrm{CH} \text { e Calcarea } \\
\text { carbonica } 12 \mathrm{CH}\end{array}$ & Nada digno de nota \\
\hline
\end{tabular}


Como mostra a Tabela 1, as propriedades que faziam uso de medicamentos homeopáticos Unicistas, tiveram mais resultados satisfatórios no tratamento da mastite do que aquelas que usavam compostos homeopáticos comprados em lojas agropecuárias. Apenas na propriedade de Marechal Rondon no Paraná, os autores relataram que não houve resultados significativos no tratamento entre os medicamentos alopáticos e homeopáticos (MULLER et al., 2013). Já nas propriedades apresentadas na Tabela 2, as quais usavam algum antibiótico alopático para tratamento da mastite, a maioria apresentou bactérias resistentes a alguns medicamentos.

Tabela 2 - Dados sobre resistência antibiótica em algumas propriedades.

\begin{tabular}{|c|c|c|c|c|c|}
\hline Autores & Propriedades & $\begin{array}{l}\text { Amostras de } \\
\text { leite positivas }\end{array}$ & Local & $\begin{array}{l}\text { Bactérias } \\
\text { isoladas }\end{array}$ & $\begin{array}{l}\text { Resistencia aos } \\
\text { antibióticos }\end{array}$ \\
\hline Castro et al. (2012) & 10 & 54 & $\begin{array}{l}\text { Barra Mansa e Resende- } \\
\text { RJ }\end{array}$ & $\begin{array}{l}\text { S. aureus } \\
\text { E. Coagulase } \\
\text { Negativo } \\
\text { S. agalactiae, } \\
\text { S. uberis }\end{array}$ & $\begin{array}{l}\text { ampicilina, } \\
\text { gentamicina } \\
\text { cloranfenicol }\end{array}$ \\
\hline Martins et al. (2014) & 7 & 332 & $\begin{array}{l}\text { Abadia de Goiás, } \\
\text { Anápolis, Bela Vista, } \\
\text { Goiânia, Hidrolândia, } \\
\text { Silvânia e Turvânia-GO }\end{array}$ & $\begin{array}{l}\text { Staphylococcus spp. } \\
\text { e S. uberi }\end{array}$ & ampicilina \\
\hline Costa et al. (2013) & 35 & 352 & $\begin{array}{l}\text { Municípios de Minas } \\
\text { Gerais }\end{array}$ & S. aureus & $\begin{array}{l}\text { polimixina } \\
\text { penicilina, } \\
\text { ampicilina, } \\
\text { lincomicina } \\
\text { tetraciclina }\end{array}$ \\
\hline Krewer et al. (2013) & 7 & 2064 & $\begin{array}{l}\text { Região do Vale do São } \\
\text { Francisco- PE }\end{array}$ & Staphylococcus spp & $\begin{array}{l}\text { tetraciclinas e a } \\
\text { estreptomicina, }\end{array}$ \\
\hline Girardini et al. (2016) & 1 & 1.060 & Agreste- PE & $\begin{array}{l}\text { Staphylococcus } \\
\text { aureos }\end{array}$ & penicilina \\
\hline
\end{tabular}

Embora nas análises pesquisadas não fique explicito que as propriedades faziam uso constante de certos antibióticos, o teste bacteriológico realizado mostrou que há resistência bacteriológica a ampicilina, penicilina, amoxicilina e neomicina (ACOSTA et al., 2016). Essa resistência aos antimicrobianos é o maior responsável pela disseminação bacteriana nos rebanhos associado com mudanças no manejo, como o uso indiscriminado de antimicrobianos e o uso da 
ordenhadeira mecânica em condições precárias de higiene (COSTA et al., 2013; NERES et al., 2015).

No trabalho de Garcia et al. (2017) realizado com 20 amostras de leite de búfalas provindos de fazendas da região de São Paulo, as fêmeas em lactação apresentaram mastite subclínica e nos exames antimicrobianos, as bactérias com maior incidência foram Staphylococcus epidermidis, Staphylococcus aureus, Bacillus spp, e E. coli, constatou-se que essas bactérias ainda não representam resistência aos antibióticos. Para S. aureus e S. epidermidis os maiores percentuais de sensibilidade observados foram gentamicina (100\%) e vancomicina (100\%); para o gênero Streptococcus à gentamicina e oxacilina e para E. coli à ampicilina.

Para Sundrum and Keller (2016) a falta de conhecimento dos produtores representa o maior problema na aplicação dos medicamentos homeopáticos. Em pesquisa realizada em 59 fazendas ecológicas e 5 convencionais, na Alemanha (20), França (20) e Espanha (24), que utilizam produtos homeopáticos, foi avaliado através de dois questionários os pré-requisitos para a aplicação do medicamento e o nível de conhecimento do aplicador, constatou-se que em cada país a anamnese era feita seguindo critérios diferentes dos estipulados pelo médico alemão Samuel Hahnemann (referência em homeopatia), desse modo, os medicamentos escolhidos divergiam e não apresentavam os resultados esperados, consequentemente não ocorria a cura dos animais e o uso dos medicamentos era interrompido.

\section{CONSIDERAÇÕES FINAIS}

A homeopatia pode se tornar eficiente no controle e tratamento da mastite, desde que seja aplicada a anamnese correta e usado apenas um composto como escolha ao tratamento por vez.

Há necessidade de mais estudos e pesquisas homeopáticas tanto no Brasil como em outros países, pois as poucas pesquisas não apresentam um número quantitativo adequado de animais tratados, demonstrando que não há diferenças entre a administração de um placebo e de um medicamento homeopático.

\section{REFERÊNCIAS}

ACOSTA, A. C.; SILVA, M.; JUNIOR, J. W. P ; MOTA, R. A. Mastite em ruminantes no Brasil. Pesquisa Veterinária Brasileira, v.36, p.565-573, 2016.

ALVES, L. C. Q. Uso de terapias veterinárias convencionais e naturais em assentamento de

Reforna Agrária. Dissertação de mestrado - Universidade Federal de Santa Catarina, Centro de Ciências Agrárias. Florianópolis, Santa Catarina, 2015. 142 p. 
ARCANJO, A. H. M.; OLIVEIRA, P. C. S.; MOREIRA, L. C.; JAYME, C. G.; SOARES, N. A.; OLIVEIRA, A. R.; PEREIRA, K. A ; NOGUEIRA, M. A. R. Programa dos seis pontos de contole da mastite em rebanhos leiteiros. Global Science and Tecnology; v.10, p.78-88, 2017.

CAMARGO, L. R. P. Avaliação da Atividade Antimicrobiana de Extratos vegetais de Plantas Brasileiras sobre Escherichia Coli. Dissertação de Mestrado - Instituto de Ciência da Saúde da Universidade Paulista. São Paulo, São Paulo, 2013.

CASTRO, B. G, SOUZA, M. S ; BITTENCOURT, A. J. Prevalência e etiologia da mastite subclinica na região sul Fluminense. Revista Acadêmica: Ciências Agrárias e Ambientais, v.10, p.263-268, 2012.

CASTRO, B. G.; SOUZA, M. M. S.; REGUA, M. A. H ; BITTENCOURT, A. J. Genetic relationship between Escherichia coli strains isolated from dairy mastitis and from the stable fly Stomoxys calcitrans. Pesquisa Veterinária Brasileira, v.36, p.479-484, 2016.

COSTA, G. M.; BARROS, R. A.; CUSTODIO, D. A. C.; PEREIRA, U. P.; FIGUEIREDO, D. J ; SILVA, N. Resistência a antimicrobianos em Staphylococcus aureus isolados de mastite em bovinos leiteiros de Minas Gerais, Brasil. Arquivos do Instituto Biológico; v.80, p.297-302, 2013.

DOEHRING, C ; SUNDRUM, A. Efficacy of homeopathy in livestock according to peerreviewed publications from 1981 to 2014. Veterinary Record, v.17, p.1-13, 2016.

EBERT, F.; STAUFENBIEL, R.; SIMONS, J ; PIEPER, L. Randomized, blinded, controlled clinical trial shows no benefit of homeopathic mastitis treatment in dairy cows. Journal of Dairy Science, v.100, p.4857-4867, 2017.

FRANCOZ, D.; WELLEMANS, V.; DUPRÉ, J. P.; ROY, J. P.; LACASSE, P ; DUFOUR, S, Invited review: A systematic review and qualitative analysis of treatments other than conventional antimicrobials for clinical mastitis in dairy cows. Jounal of Dairy Science, v.100, p.7751-7770, 2017.

FREITAS, A. P. D. G. Preparados Homeopáticos na Produção Leiteira de Camponeses: Estudo de caso. Dissertação de mestrado - Universidade Federal de Santa Catarina. Florianópolis, agosto de 2015. 120p.

GIRARDINI, L. K.; PAIM, D. S.; AUSANI, T. C.; LOPES, G. V.; PELLEGRINI, D. C. P.; BRITO, M. P. V. P ; CARDOSO, M. Antimicrobial resistance profiles of Staphylococcus aureus clusters on small dairy farms in southern Brazil. Pesquisa Veterinária Brasileira, v.36, p.951-956, 2016.

KREWER, C. C.; LACERDA, L. P. S.; AMANSO, E. S.; CAVALCANTE, N. B.; PINHEIRO, M. R.; COSTA, J. W.; MOTA, M. M ; PEIXOTO, R. A. Etiology, antimicrobial susceptibility profile of Staphylococcus spp, and risk factors asssociate with bovine mastitis in the states of Bahia and Pernambuco. Pesquisa Veterinária Brasileira, v.33, p.601-606, 2013.

LANGONI, H. Qualidade do leite: utopia sem um programa sério de monitoramento da ocorrência de mastite bovina. Pesquisa Veterinária Brasileira, v.33, p.620-626, 2013.

LEAL, L. P ; COSTA, C. Utilização da homeopátia para redução da contagem de células somáticas (CCS) em vacas Girolando. PUBVET, Publicações em Medicina Veterinária e Zootecnia; v.7, p.1562, 2013. 
MARTINS, D. J, NICOLAU, E. S, MESQUITA, A. J ; JARDIM, E. A. G. V. Mastite subclinica em rebanhos leiterios de propriedades rurais de Goiás. Revista Brasileira de Higiene e Sanidade Animal; v.9, p.206-214, 2015.

MASSIGNANI, C. Qualidade do leite de vacas submetidas a tratamento homeopático para mastite. 2015. Disponivel em:

<https://repositorio.ufsc.br/bitstream/handle/123456789/159999/TCCVERSÃOFINAL08_12caro line \%20pdf.pdf? sequence=1;isAllowed=y $>$ Acesso em 20/04/2018.

MULLER, S. F ; FULBER, V. M. A Homeopatia na pecuária leiteira: da capacitação aos resultados práticos. Resumos do VIII Congresso Brasileiro de Agroecologia. Caderno de Agronomia, v.8, 2013.

NEIVA, R. Estagnada em 2018, pecuária de leite deve crescer este ano. Embrapa - Estudos socioeconômicos e ambientais. 2019. Disponivel em: https://www.embrapa.br/busca-denoticias/-/noticia/40556629/estagnada-em-2018-pecuaria-de-leite-deve-crescer-este-ano >Acesso em 01/04/2020.

NERES, W. S.; SANTOS, O. M.; TUÑON, G ; CARNEIRO, M. R. P. Susceptibilidade antimicrobiana de Staphyloccocus coagulase positiva isolada de vacas com mastite em Sergipe.

Scientia Plena, v.11, p.1-6, 2015.

NEUFELDT, C. D.; VICTOR, B. P.; MARTINS, A. S ; CARNEIRO, A. S. No effects of homeopathy on somaticcell count, bovine milk yied and composition. Acta Veterinaria Brasilica, v.11, p.14-19, 2017.

OLIVEIRA, J. P.; RANGEL, F. A. H. N.; BARRETO, M. L. J.; JUNIOR, D. M. L.; URBANO, S. A ; AURELIANO, I. P. L. Fatores de risco para a mastite e qualidade do leite no municipio de Altônia-PR. Arquivos de Ciências Veterinárias e Zoologia da UNIPAR, v.16, p.61-72, 2013.

ORJALES, I.; ALONSO, M. L.; BERMÚDEZ, R. R.; VILLAR, A.; CRESPO, F. R ; MIRANDA, M., Use of homeopathy in organic dairy farming in Spain. Hemeopathy, v.105, p.102-108, 2016.

POZZI, G. J. R ; NETO, M. M. Conflitos entre a Produção Orgânica em Grande Escala e a Agroecologia: O caso da Fazenda da Toca. Interface Tecnológica, v.1, p.332-347, 2017.

ROSSI, G. A. M ; LEMOS, P. P. L. Comparação da Produção Animal entre os Sistemas Orgânicos e Convencional. Revista de Educação Continuada em Medicina Veterinária e Zootecnia do CRMV-SP, v.11, p.6-13, 2013.

SAROLLI, V. M. M.; ZIMERMANN, S. S.; COMIRAN, T. B ; IASCHOMBERCK, C. T. Características, formas de contaminação, tratamentos existentes e métodos de prevenção da mastite bovina: uma revisão bibliográfica. Thêma et Scientia, v.6, p.297-309, 2016.

SUNDRUM, A ; KELLER, D 2016, Behandlungen mit Homöopathika auf Milchviehbetrieben erfolgen selten zielorientiert. Acesso em 02/03/2018. < http://orgprints.org/31818/1/Behandlungen\%20mit\%20Homöopathika\%20auf\%20Milchviehbetri eben.pdf>.

TRONCARELLI, M. Z.; BRANDÃO, H. M.; GUIMARÃES, J. C.; GERN, A. S ; LANGONI, H. Mastite bovina sob nanocontrole: A própolis nanoestruturada como nova perspectiva de tratamento para rebanhos leiteiros orgânicos.Veterinária e Zootecnia, v.20, p.124-136, 2013. 